\title{
手性烯烃配体在不对称催化领域的最新进展
}

\author{
冯向青杜海峰* \\ (中国科学院化学研究所 北京分子科学国家实验室 分子识别与功能院重点实验室 北京 100190)
}

\begin{abstract}
摘要 手性烯烃配体是一类具有重要应用前景的新型配体, 自发展以来就引起化学家们的广泛关注. 手性烯烃配体在 一些反应中表现出比传统氮、磷、氧配体更高的活性和选择性, 实现了一些使用其它类型配体不能实现的化学转化. 为 了增强手性烯烃配体与金属的配位能力，化学家们在其骨架上引入杂原子, 发展得到混合型的烯烃配体, 增加了配体 的多样性, 对进一步拓展手性烯烃配体的类型和应用具有非常重要的意义. 目前关于手性烯烃配体已经有一些综述, 本综述将着重介绍最近几年来发展的手性开链双烯配体、手性膦烯烃配体和手性硫烯烃配体及其在过渡金属催化的不 对称反应领域的应用.
\end{abstract}

关键词＼cjkstart手性烯烃配体；不对称催化；手性双烯配体；手性膦烯配体；手性硫烯配体

\section{Application of Chiral Olefin Ligands in Asymmetric Catalysis}

\author{
Feng, Xiangqing Du, Haifeng* \\ (Beijing National Laboratory for Molecular Sciences, CAS Key Laboratory of Molecular Recognition and Function, \\ Institute of Chemistry, Chinese Academy of Sciences, Beijing 100190)
}

\begin{abstract}
As a novel class of potential ligands, chiral olefin ligands have attracted much attention. Chiral olefin ligands exhibit higher activity and selectivity than the traditional nitrogen, phosphine, oxide ligands in some reactions, and solved some problems that other ligands could not do. To enhance the coordination of the olefin ligands and the metal, heteroatoms were introduced to its backbone, several hybrid olefin ligands have been developed to increase the diversity of the ligands for further expanding the application of chiral olefin ligands. In this review, the recent advances in the development of chiral diene ligands, chiral phosphine olefin ligands and chiral sulfur olefin ligands, and their application in transition-metal catalyzed asymmetric reactions are reviewed.
\end{abstract}

Keywords chiral olefin ligand; asymmetric catalysis; chiral diene ligand; chiral P/alkene ligand; chiral S/alkene ligand

烯烃 ${ }^{[1]}$ 作为配体有着悠久的历史, 广泛存在于各类 过渡金属络合物中. 然而这些络合物通常不太稳定，烯 烃容易从金属上解离, 被其它强配位配体取代, 因此这 些络合物通常作为重要的催化剂前体应用于反应中, 而 利用手性烯烃配体 ${ }^{[2]}$ 调控反应的活性和对映选择性极具 挑战性.

直到 2003 年, Hayashi 等 ${ }^{[3]}$ ]报道了首例 $C_{2}$ 对称的手 性[2.2.1]降冰片二烯衍生物 $\mathbf{1}$ 作为手性配体, 用于金属 铑催化的芳基硼试剂对不饱和酮或不饱和酯的 1,4-加成 反应, 得到了非常高的催化活性和对映选择性. 随后, Carreira等 ${ }^{[36]}$ 报道的 $C_{1}$ 对称的手性[2.2.2]双烯 2 , 在铱催 化的烯丙基碳酸酯的动力学拆分反应中也得到了优秀
的结果. 从此手性烯烃配体的开发引起了化学家们的重 视, 围绕着不对称催化而设计的手性烯烃配体陆续出 现，在诱导不对称催化反应中取得很好的效果. 这些手 性双烯配体在有些反应中甚至表现出比传统氮、磷、氧 配体更高的活性和选择性，实现了一些利用其它类型配 体难以实现的化学转化, 由此可见, 手性烯烃配体是一 类具有重要应用前景的新型配体. 林国强院士在这一领 域也做出了突出的贡献. 2007 年, 林国强小组 $\left.{ }^{[4]}\right]$ 报道了 新型的 $C_{2}$ 对称的手性[3.3.0]环戊二烯骨架的双烯配体 3, 并实现了高效的亚胺的芳基化反应. 随后, 他们发展 的两类并环双烯配体分别在铑催化的芳基嗍试剂对不 饱和酮的 1,4-加成反应 ${ }^{[\mathrm{bb}]}$ 和亚胺的 1,2-加成反应 ${ }^{[4 \mathrm{c}]}$ 中取

\footnotetext{
* E-mail: haifengdu@iccas.ac.cn

Received September 11, 2014; revised October 16, 2014; published online October 22, 2014.

Project supported by the National Natural Science Foundation of China (No. 21222207).

国家自然科学基金(No. 21222207)资助项目.
} 
得了优秀的结果.

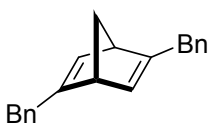

1 Hayashi, 2003 Ref. [2]<smiles>C1=CC2(OCCO2)C2C=CC3(OCCO3)C12</smiles>

Lin \& Xu, 2008 Ref. [4b]

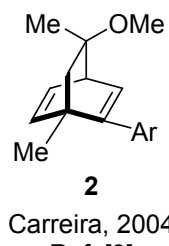

Ref. [3]

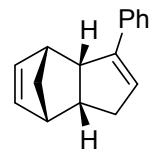

Lin \& Feng, 2010

Ref. [4c]

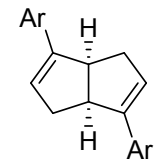

3

Lin \& Xu, 2007

Ref. [4a]
由于烯烃与金属的配位能力相对较弱, 为了增强手 性烯烃配体与金属的配位能力, 化学家们通过在其骨架 上引入磷、氮、硫等杂原子来实现. 不同配位元素的组 合增加了配体的多样性, 甚至可能具有更加优越的催化 性能，通过各种配体的优化篮选，可以找到更好的手性 配体应用于不对称催化反应. 混合型的手性烯烃配体对 进一步拓展手性烯烃配体的类型和应用, 具有非常重要 的意义. 目前发展的手性混合烯烃配体主要应用于不对 称烯丙基取代反应和芳基硼试剂对不饱和酮的 1,4-加成 反应中.

目前关于手性烯烃配体已经有一些文献综述, 前期 的综述侧重于介绍刚性骨架的手性双烯以及膦烯烃配 体, 2012 年, 我们也系统总结了 2009 年以来本课题组在 这一领域的研究成果, 最近徐明华小组发表了关于手性 硫烯烃配体的最新进展. 本文主要结合本课题组的工 作, 对最近几年来发展的手性开链双烯配体、手性膦烯 烃配体以及手性硫烯烃配体的应用进展进行详细的介 绍.

\section{1 手性开链双烯配体}

已经报道的手性双烯配体通常具有双环刚性骨架， 在某种程度上, 这种骨架结构是反应具有高催化活性和 高对映选择性的保证，但同时也带来制备和修饰上的一 系列困难. 与刚性骨架的手性双烯配体相比, 链状双烯 具有柔性的骨架结构更易于合成和修饰, 很多具有开链 结构的双烯虽然是已知物, 但是作为配体用于不对称催 化反应还没有报道.

2009 年, 杜海峰小组 ${ }^{[5]}$ 在研究中发现, 简单的 $1,5-$ 已二烯在铑催化的苯硼酸 (7a) 对 2-环已烯酮 (6a)的共轭 加成反应, 可以得到当量的转化, 这表明链状双烯可以 作为这类反应的高效配体. 受此结果启发, 该小组以天 然甘露醇和 $L$-酒石酸出发, 合成了一系列含不同保护基
的二醇类链状手性双烯化合物, 将此类柔性骨架的手性 双烯应用于铑催化的芳基硼酸对 $\alpha, \beta$-不饱和羰基化合物 的 1,4-加成反应中, 发现其中配体 9a 有很高的催化活 性，可以以 $61 \%$ 的对映选择性当量的得到加成产物 $8 \mathrm{a}$ (Eq. 1). 而将末端的乙烯基换为乙基时，反应几乎不能 发生; 使用两个羟基被保护的配体 9c，反应的活性和对 映选择性都有不同程度的降低，由此可见，配体通过烯 基与金属配位，游离的羟基和烯烃对反应都是至关重要 的.
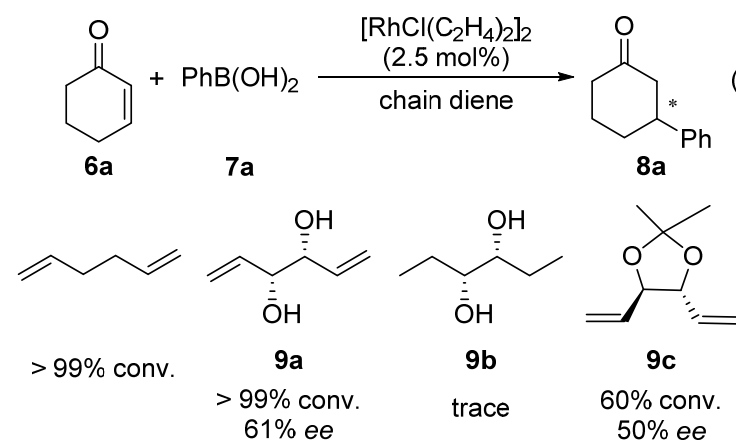

随后杜海峰小组使用史一安小组发展的钯催化的 对 1,5-己二烯的不对称双胺化反应 ${ }^{[6]}$ ，一步合成含有咪 唑啉酮骨架的手性双烯配体 $\mathbf{1 1}^{[7]}$, 通过一次重结晶得到 光学纯的手性双烯配体(Eq. 2). 以铑催化的芳基硼酸对 环状 $\alpha, \beta$-不饱和羰基化合物的共轭加成反应为模型反 应，产物的对映选择性最高可以达到 $85 \%$ ee.

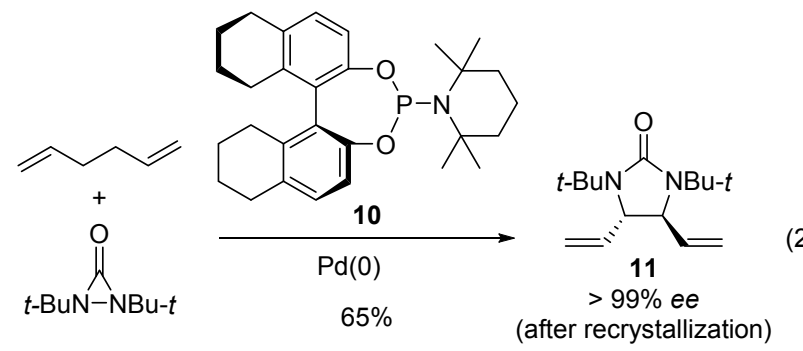

为了寻找更加高效高选择性的开链双烯配体, 杜海 峰小组将配体 11 通过脱除叔丁基和羰基，并在 $\mathrm{N}-\mathrm{H}$ 上 引入 $\mathrm{Ms}$ 基团, 合成手性二胺双烯配体 $\mathbf{1 2}^{[8]}$. 这类配体 同样在铑催化的 1,4-加成反应中有优秀的表现，可以以 54\% 99\%的产率和 $76 \%$ \% $95 \%$ 的对映选择性得到加成 产物 8 (Eq. 3).

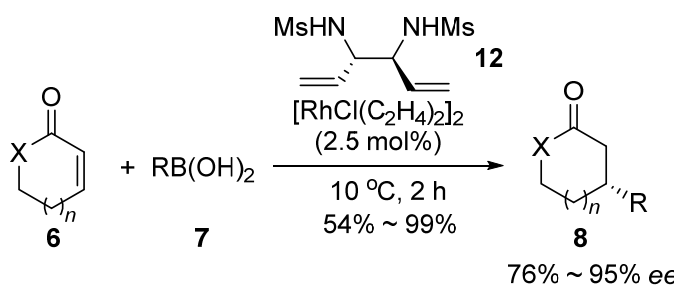


2010 年, Boysen 等 ${ }^{[9 b]}$ 从 $D$-葡萄糖和 $D$-阿拉伯糖出 发, 经过几步化学转化, 得到含二氢吡喃环的手性双烯 13, 在苯硼酸对 2-环已烯酮的 1,4-反应中, 可以得到中 等的产率，但是手性控制还不是很理想.

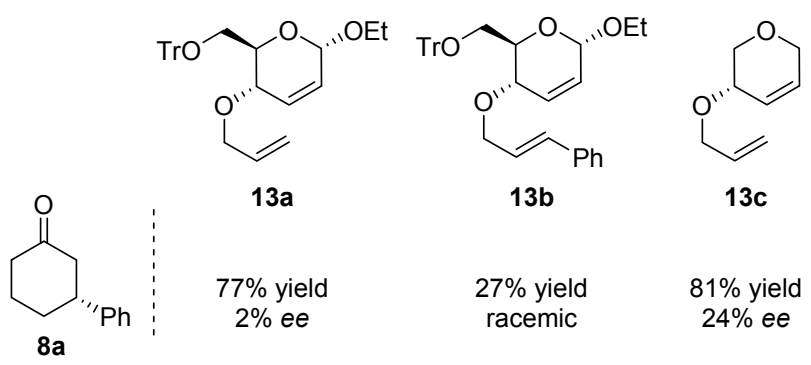

2011 年, 余志祥小组 ${ }^{[10 a]}$ 利用铑催化三烯体的烯丙 基 $\mathrm{C}-\mathrm{H}$ 活化-加成反应制备手性 $\alpha, \beta$-二乙烯基四氢吡 咯 16, 将其作为配体用于铑催化的芳基硼酸对环状 $\alpha, \beta$ 不饱和羰基化合物的共轭加成，可以达到 90\% 98\% 的对映选择性 ${ }^{[106]}$, 这说明顺式手性双烯也可以催化不 对称反应(Eq. 4). Trost 小组 ${ }^{[11]}$ 通过钯催化的不对称烯丙 基取代反应合成的开链手性双烯配体 19 (Eq. 5), 以及 Carbery 小组 ${ }^{[2]}$ 以天然手性源 $L$-丝氨酸为原料合成的含 有噁唑啉环的开链双烯配体 20, 在芳基硼酸对 2-环己 烯酮的反应中，都有优秀的表现(Scheme 1).
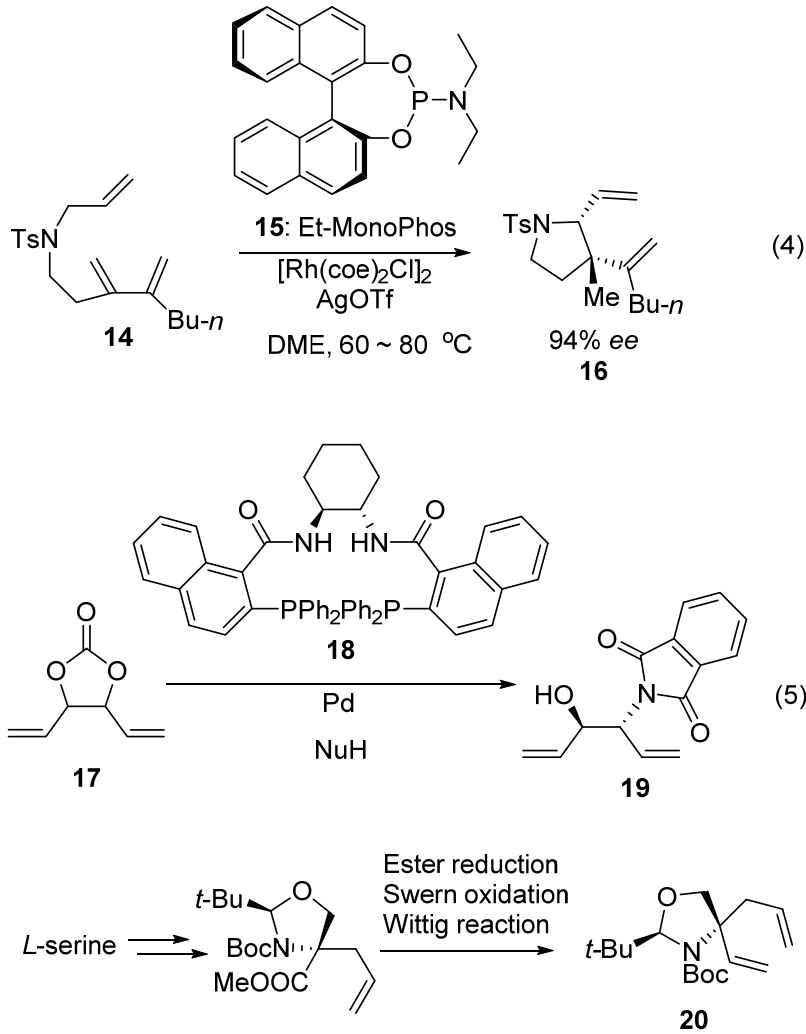

图式 1 从天然手性源合成噁唑烷基手性二烯配体 Scheme 1 The synthesis of oxazolidinyl chiral diene ligands from natural chiral source
含有轴手性联䒺骨架的手性配体在不对称催化领 域有着广泛的应用. 杜海峰小组从简单的手性 BINOL 出发, 合成了一类具有联䒺骨架的手性双烯配体 22. 这 类配体可以应用于铑催化的芳基硼酸 7 对 $N, N$-二甲基磺 酰基保护的酫亚胺 21 的芳基化反应中，可以以中等到 良好的产率和最高 $84 \%$ 的对映选择性得到二芳基甲基 胺 23 (Eq. 6) ${ }^{[13]}$. 产物可以在微波条件下脱除保护基, 得 到光学活性的二芳基胺.

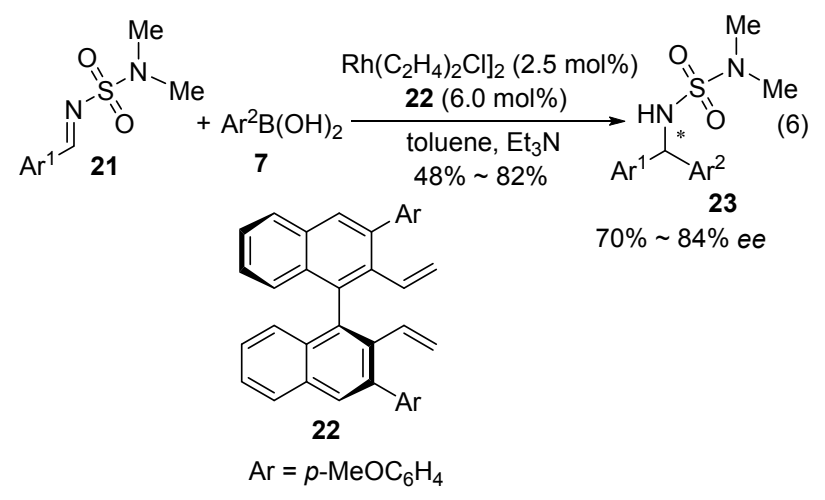

\section{2 手性膦烯烃配体}

尽管双齿鳌合的手性烯烃配体得到了很大的发展， 但是由于烯烃与金属的配位, 是 $\pi$ 电子与过渡金属的空 $\mathrm{d}$ 轨道结合, 不同于一般的磷原子或者氮原子, 所以它 与金属配位的能力相对较弱, 容易在催化反应的过程中 解离而失去活性. 为了增加手性烯烃配体与金属的配位 能力, 化学家们在手性烯烃骨架上引入磷原子或者氮原 子来增强配体的配位能力. 同时, 不同配位元素的组合 也可以增加配体的多样性，对各种配体进行优化筛选， 可以找到更好的手性配体应用到不对称催化反应中去. 不同配位因素的组合甚至可能具有更加优越的催化性 能，拓展手性烯烃配体在不对称催化领域的应用. 目前 报道的手性膦烯烃配体 ${ }^{[14]}$ 也有很多，我们将代表性分 类对其应用进行介绍.

2004 年, Grützmacher 等 ${ }^{[15 a]}$ 率先报道了二苯基并七 元环的手性膦烯烃配体 25a, 催化亚胺的氢化达到较好 的对映选择性(Eq. 7). 相似结构膦烯烃配体 25b 可以催 化芳基硼酸对 2-环已烯酮的加成反应，ee 值可达 95\%, 同时其对 $N$-苄基马来酰亚胺也能够高效地诱导加成产 物的手性 $(80 \% e e)^{[15 b]}$.

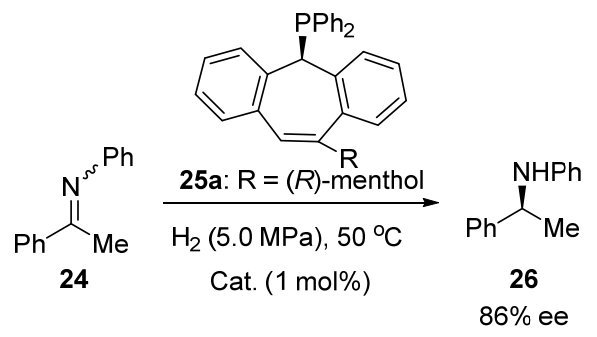


<smiles>O=C1CCC[C+](c2ccccc2)C1</smiles>

$8 \mathbf{a}$
$95 \%$<smiles>O=C1CC(c2ccccc2)C(=O)[NH2+]1</smiles>

27

$80 \%$ ee<smiles>O=C(c1ccccc1)c1ccccc1C(c1ccccc1)c1ccccc1</smiles>

25b
2005 年, Hayashi 小组 ${ }^{[16]}$ 通过 HPLC 拆分得到基于 双环 $[2,2,1]$ 骨架的手性膦烯烃配体 29, 这类配体可以高 效地诱导产物的立体选择性. 在苯硼酸对 2-环已烯酮的 加成反应中, 可以得到 $94 \%$ 的产率和 $93 \%$ 的对映选择 性; 苯硼酸对 $N$-苠基马来酰亚胺的加成可达 $97 \%$ 的产 率和 $95 \% e e^{[16 a, b]}$. 同时, 该类配体还可以用于钯催化的 烯丙基烷基化反应，以 $87 \%$ 的产率和 $96 \%$ ee 得到相应 的产物 ${ }^{[16 \mathrm{c}]}$.<smiles>O=C1CCC[C@H](P)C1</smiles>

8a $93 \%$ ee<smiles>O=C1CC(c2ccccc2)C(=O)[NH2+]1</smiles>

27 97\%yield $95 \%$ ee<smiles>CC(=O)C(C(C)=O)C(/C=C/c1ccccc1)c1ccccc1</smiles>

28a $87 \%$ yield $96 \%$ ee<smiles>[R]C1CC2CC1C2Pc1ccccc1</smiles>

29a: $R=P h$ 29b: $\mathrm{R}=4-\mathrm{CF}_{3} \mathrm{C}_{6} \mathrm{H}_{4}$
由于配体 29 合成的路线比较长, 需要进行手性拆 分, Hayashi 小组对该配体进行了简化, 合成了 1-(二苯 基膦)-2,5-二氢-1 $H$-吡咯骨架的手性膦烯烃配体 30. 在 $N$-Ts-亚胺的芳基化反应中, 配体 30a 可以得到与配体 29a 相当的产率和对映选择性 ${ }^{[17 \mathrm{a}]}$. 此外, 这类配体还可 以用于铑催化的不对称 1,4-加成反应, 通过调整配体 $\alpha$ 和 $\beta$ 位的取代基，可以得到构型相反的产物 ${ }^{[17 b]}$.

此外, 基于面手性的二茂铁骨架 ${ }^{[18]}$ 以及环戊二烯铼络合物 ${ }^{[19]}$ 衍生的膦烯烃配体也被合成出来, 如配体 33 和 34, 但是其诱导催化不对称反应的效果不是很理 想, 在芳基硼酸对 2-环已烯酮的加成反应中可以得到中 等到较好的对映选择性.

2014 年, Ogasawara, Takahashi 和 Kamikawa 小 组 ${ }^{[20]}$ 从光学纯的 $\pi$-芳烃-铬络合物出发, 合成得到面手 性的膦烯烃配体 35. 这类配体不仅在铑催化的芳基硼 酸对 $\alpha, \beta$-不饱和酮的加成反应中得到优秀的结果, 在钯 催化的不对称烯丙基取代反应中也可以以中等的产率 得到高达 $94 \%$ 的对映选择性.<smiles>Pc1ccccc1</smiles>

(7R)-29a<smiles>O=C([Na])NC(c1ccccc1)c1ccc(Cl)cc1</smiles><smiles>O=C1CCCC(c2ccccc2)C1</smiles>
$89 \%, 94 \%$ ee $(S)$ $8 a$<smiles>C1=C(c2ccccc2)CN(Pc2ccccc2)C1Cc1ccccc1</smiles>

(S)-30a
(S)-30b

$91 \%, 96 \%$ ee $\quad 90 \%, 97 \%$ ee<smiles>CC1=CC(Cc2ccccc2)N(Pc2ccccc2)C1</smiles>

(S)-30c<smiles>CC(=O)CC(C)c1ccccc1</smiles>

$89 \%, 85 \%$ ee $(R) \quad 79 \%, 50 \%$ ee $(S)$

2009 年, Boysen 小组 ${ }^{[21]}$ 从商品化的 2,3-不饱和吡喃 糖苷出发, 经过简单的三步化学转化, 得到手性膦烯烃 配体 37 (Scheme 2), 这类配体在铑催化的 1,4-加成反应 和钯催化的不对称烯丙基取代反应中都有较好的表现 (Eq. 8).

综合以上结果可以发现，手性膦烯烃配体的应用仍 集中于铑催化的加成反应和钯催化的烯丙基取代反应, 反应类型还比较少. Carreira 小组发展了亚磷酰胺一烯烃 配体 40 和 41, 在铱催化的不对称反应中有很好的表现, 拓展了手性膦烯烃配体的应用.

2007 年, Carreira 小组 ${ }^{[22 a]}$ 首次使用氨基磺酸作为氮 源，实现了支链烯丙基醇的烯丙基胺化反应. 当使用非 手性的联苯类膦烯烃配体时，反应可以得到较好的产 率; 换用联䒺骨架的轴手性膦烯烃配体 $(S)-\mathbf{4 0}$ 时, 反应 可以得到中等的对映选择性，这也是首例铱催化的直接 从烯丙醇合成烯丙胺的报道. 随后该小组使用光学纯的 底物, 非手性的联苯类膦烯烃配体, 在反应中添加碘化 锂, 可以对映选择性保持地得到相应的烯丙基胺(Eq. $9)^{[22 b]}$.

2011 年, Carreira 小组将手性亚磷酰胺一烯烃配体 (R)-40 用于铱催化的烯丙基醚化反应，其中使用烯丙基
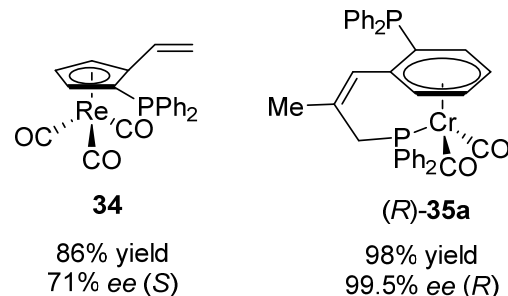


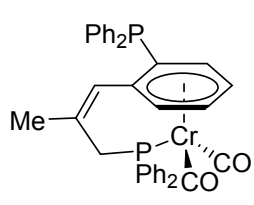

(R)-35a

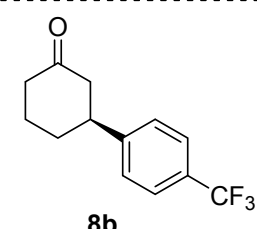

8b

(S)-35b $95 \%, 97 \%$ ee $(S)$

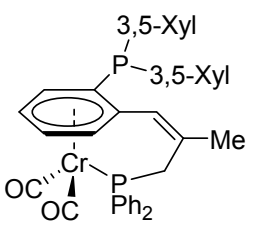

(S)-35b<smiles>O=C1C[C@H](P)C(=O)[C@@H]1c1ccccc1</smiles>

$27 \mathrm{Ph}$

R)-35a $85 \%, 81 \%$ ee $(R)$

(S)-35b 83\%, 94\% ee (S)<smiles>O=C1C=C(P)CC1</smiles>

$8 c$

(R)-35a 95\%, 99.5\% ee $(R)$ (S)-35b $92 \%, 95.5 \%$ ee $(S)$<smiles>O=C1CC(c2ccccc2)CCO1</smiles>

8d
(R)-35a $89 \%, 99.4 \%$ ee $(R)$

(S)-35b 95\%, 95.5\% ee (S)<smiles>CC(=O)CC(C)P</smiles>

32

(R)-35a 31\%, 57\% ee $(R)$

(S)-35b 34\%, 88\% ee (S)<smiles>COC(=O)CC(C=Cc1ccccc1)c1ccccc1</smiles>

28a
(R)-35a 41\%, 74\% ee (S)

(S)-35b 68\%, 94\% ee (R)

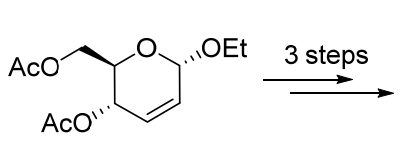

36<smiles>CCOC1C=CC(O)C(CO)C1O</smiles>

37

gluco-enoPhos

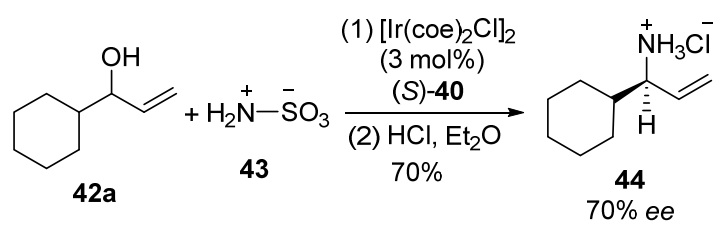

底物, 可以高选择性地得到同一构型的产物 (Scheme $3)^{[23]}$.

Scheme 2 Preparation of the alkene-phosphinite-hybrid ligand from commercially available 2,3-unsaturated pyranose<smiles>O=C1CCCC(c2ccccc2)C1</smiles>

$8 \mathbf{a}$<smiles>O=C1CCCC1</smiles>

$8 \mathrm{c}$<smiles>O=C1C[C@H](c2ccccc2)CCO1</smiles>

$8 \mathrm{~d}$<smiles>CC(=O)CC(C)c1ccccc1</smiles>

32 $80 \%, 99 \%$ ee $\quad 82 \%, 99 \%$ ee $\quad 48 \%, 94 \%$ ee $\quad 90 \%, 52 \%$ ee

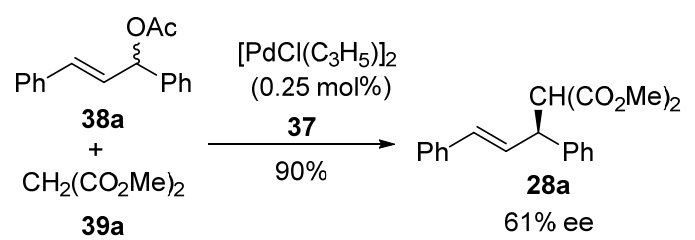

$39 a$<smiles>C1=Cc2ccccc2Nc2ccccc21</smiles><smiles>C1=Cc2ccccc2N(P2Oc3cccc4c3C3(CCc5ccccc53)c3c(cccc3O2)CC4)C1</smiles>

(S)-40

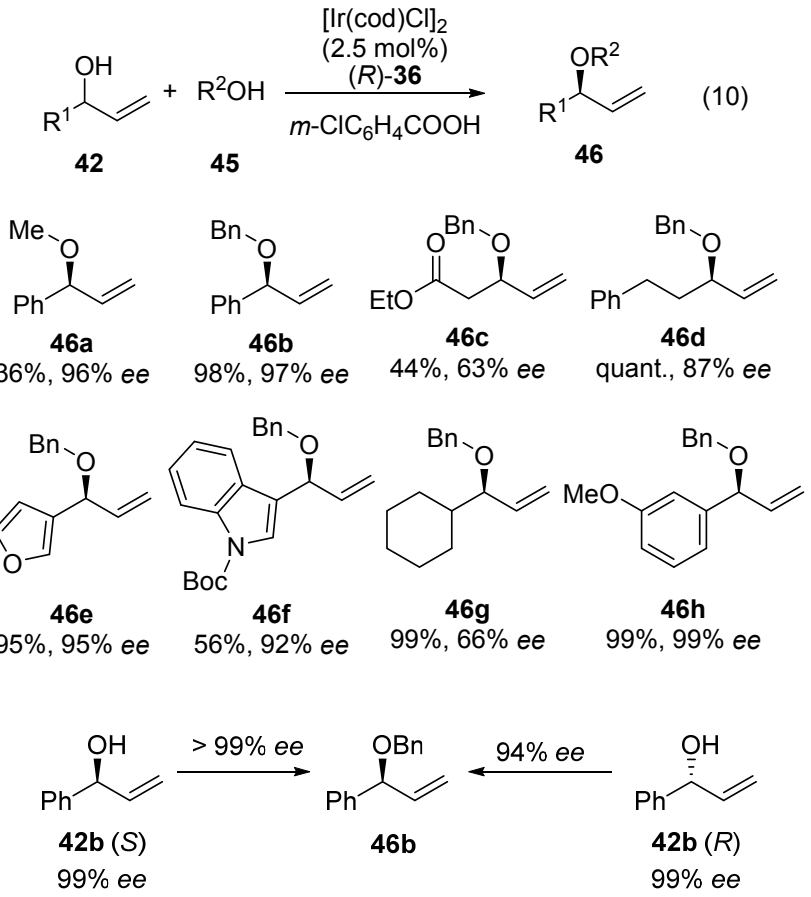

图式 3 烯丙基梄化反应的动力学拆分.

Scheme 3 The kinetic resolution of the allylic etherification

醇 42 作为亲电试剂, 脂肪醇 $\mathbf{4 5}$ 作为亲核试剂, 反应可 以高效高选择性地得到相应的醚 46 (Eq. 10). 反应过程 中涉及到烯丙基醇的动力学拆分, 使用绝对构型相反的 
亚磷酰胺一烯烃配体 $(S)$-40 在铱催化的炔基氟硼酸 钾 47 对烯丙基醇 42 的烯丙基取代反应中也有出色的表 现, 可以高效高选择性地得到支链产物, 这一方法学的 发展为一些药物的合成提供了简单直接的方法 (Eq. $11)^{[24]}$.

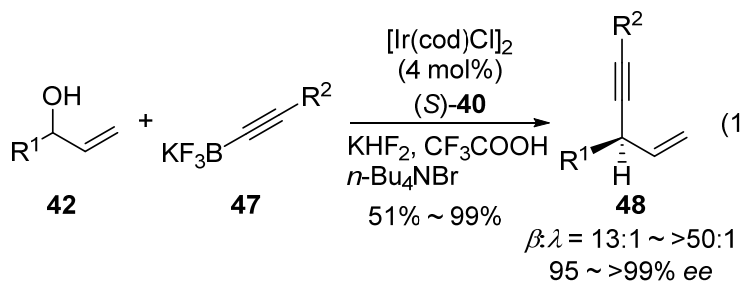

Carreira 小组 ${ }^{[25 a]}$ 使用亚磷酰胺-烯烃配体 $(R)-40$ 首 次实现了铱催化的多烯环化反应, 该反应直接对烯丙醇 进行活化，通过形成烯丙基钯中间体得到多环化产物， 最高可以得到 $>99 \%$ 的对映选择性(Scheme 4). 随后这 一方法学被应用到天然产物的合成中, 从多烯 49a 出发, 使用铱催化的对映选择性的多烯环化反应为关键步骤, 构建双碳链环，实现了天然产物 $(+)$-Asperolide $\mathrm{C}$ 的首 次全合成(Scheme 5) ${ }^{[25 \mathrm{~b}]}$.

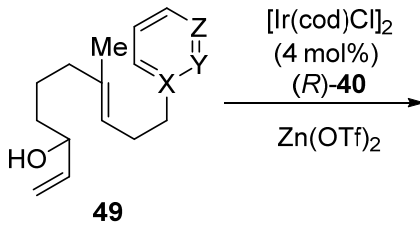

49

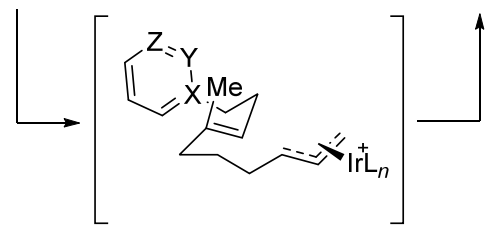

图式 4 铱催化的不对称环化反应

Scheme 4 Ir-catalyzed enantioselective cyclization

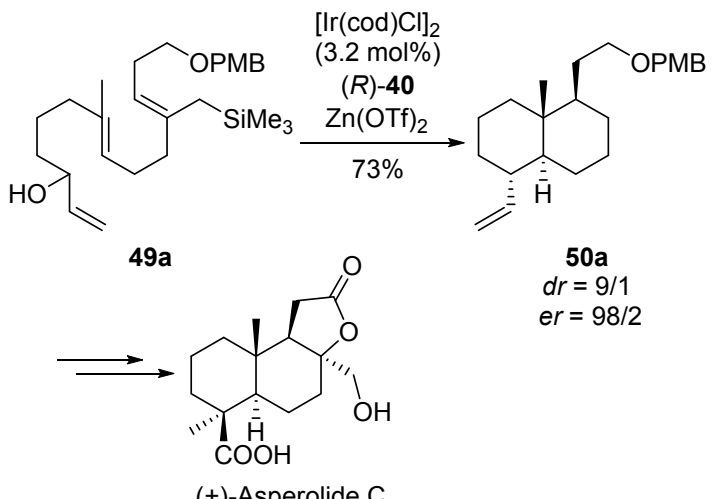

图式 5 以铱催化的不对称多烯环化反应为关键步骤实现 $(+)$-Asperolide $\mathrm{C}$ 的全合成

Scheme 5 The total synthesis of (+)-asperolide C by iridiumcatalyzed enantioselective polyene cyclization cascade
最近，手性亚磷酰胺一烯烃配体 $(R)-40$ 与双磺酰胺 52 结合, 被应用于铱催化的不对称烯丙基一烯烃偶联反 应，从简单的烯丙基醇 42 出发，直接使用烯烃 51 作亲 核试剂，以高达 20：1 的区域选择性和 $>99 \%$ 的对映选 择性的得到一系列 1,5-二烯 53 (Eq. 12). 这一方法还被 拓展应用于治疗老年痴呆症的药物 JNJ-40418677 的合 成中, 是一类非常原子经济性的反应(Scheme 6) ${ }^{[26]}$.

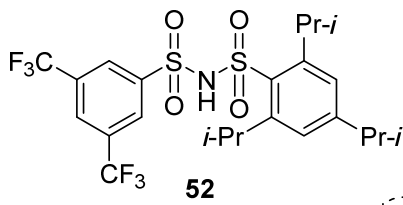

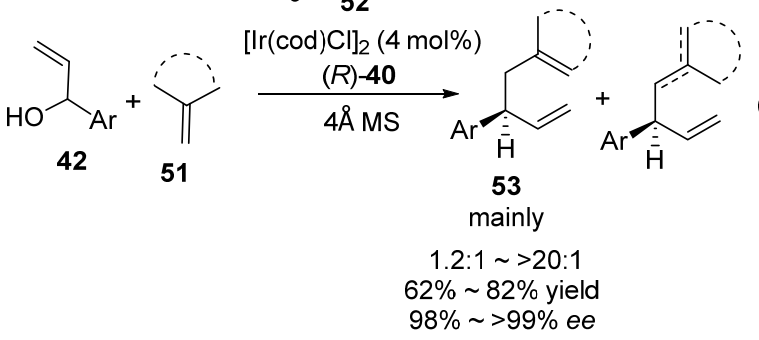<smiles>C=CC(O)c1cc([Al])cc(Br)c1</smiles><smiles>CC(C)CC(C(=O)O)c1cc(-c2ccc(C(F)(F)F)cc2)cc(-c2ccc(C(F)(F)F)cc2)c1</smiles>

JNJ-40418677, > 99\% ee

图式 6 JNJ-40418677 的不对称合成

Scheme 6 Enantioselective synthesis of JNJ-40418677

除了联䒺骨架之外，螺环骨架也被应用到手性亚磷 酰胺一烯烃配体的合成中, 2011 年, Carreira 小组 ${ }^{[27]}$ 将螺 环骨架的手性膦烯烃配体 41 用于铑催化的分子内氢酰 化反应，可以以中等到优秀的产率和 $80 \% \sim 97 \%$ 的对 映选择性得到 $\beta$-取代的环戊酮衍生物 55 (Eq. 13).

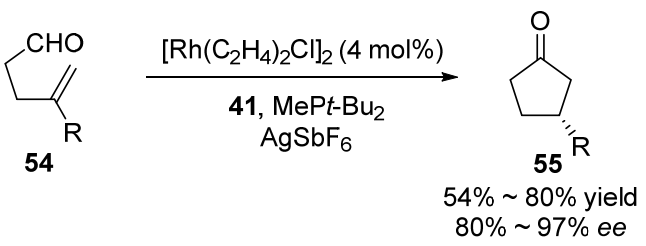

Carreira 小组最近还发展了手性膦烯烃配体与小分 
子催化剂双催化的新方法, 将手性膦烯烃配体与手性胺 结合用于醛的 $\alpha$-烯丙基化反应中, 通过手性膦烯烃配体 和手性胺的不同组合, 可以得到产物的所有的立体异构 体. 当使用金鸡纳碱衍生的手性胺 57 与手性膦烯烃配 体 $(R)-\mathbf{4 0}$ 组合时, 可以实现铱催化的对支链醛的 $\alpha$-烯丙 基化反应，对各种底物的适用性都很好，可以得到 $>$ $99 \%$ 的对映选择性和 $>20 ： 1$ 的非对映选择性 (Eq. $14)^{[28]}$.

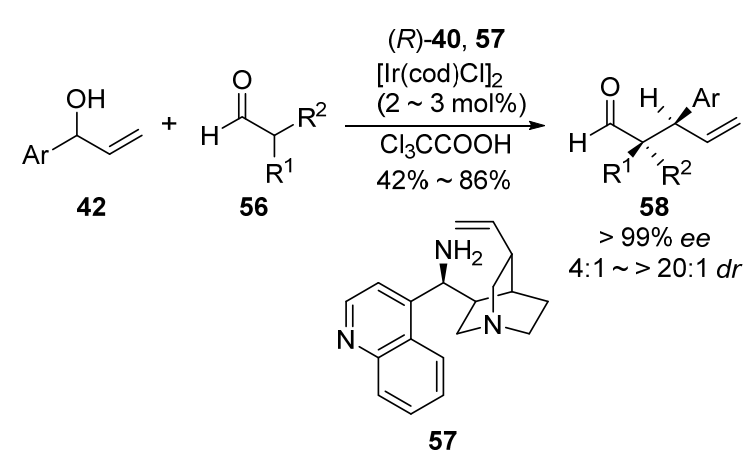

二芳基脯氨醇衍生的硅醚 59 与直链的醛原位生成 烯胺，在金属铱与配体 $\mathbf{4 0}$ 的络合物的催化下，发生烯丙 基取代反应，可以以 $>99 \%$ 的对映选择性和 $>20 ： 1$ 的 非对映选择性得到含有相邻两个手性中心的 $\gamma, \delta$-不饱和 醛(Scheme 7), 这一方法还被用于抗抑郁药(一)-帕罗西 汀的合成 ${ }^{[29]}$.

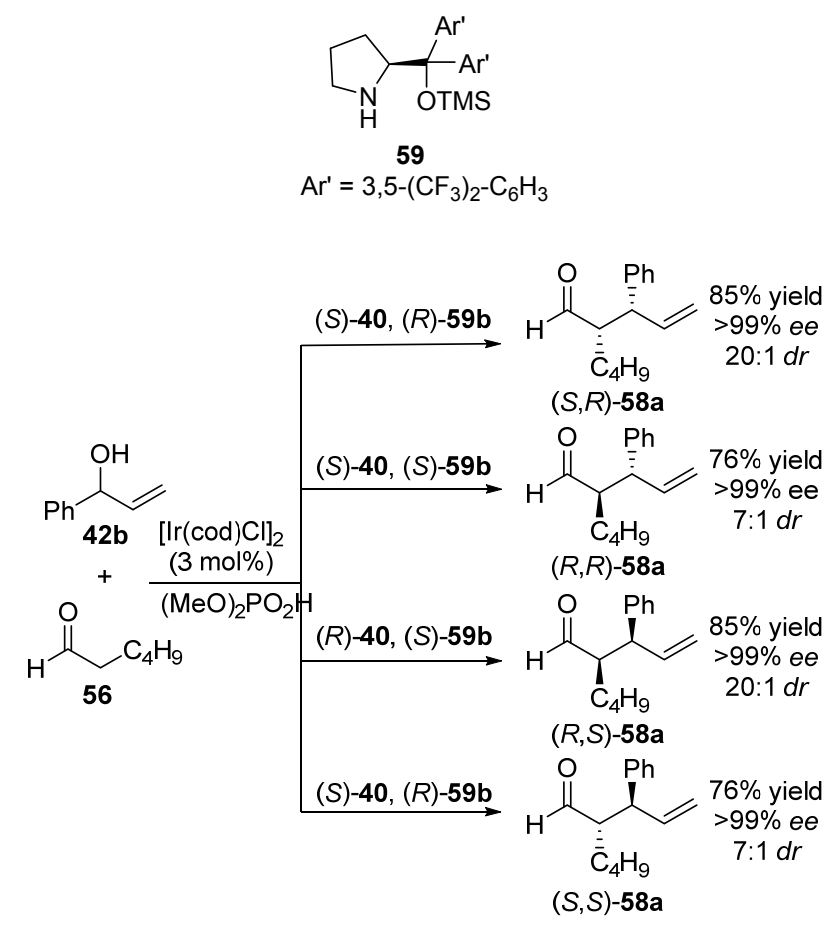

图式 7 化合物 58a 所有立体异构体的合成

Scheme 7 Synthesis of all stereoisomers of compound 58a

目前发展的手性膦烯烃配体大部分以中间烯烃作
为配位单元，而手性开链双烯配体的研究结果表明，简 单的末端烯烃配位也可以保证反应的活性和选择性. 杜 海峰小组将末端烯烃与具有更强配位能力的磷原子在 合适的手性骨架上组合，发展了几类新型的手性膦烯烃 配体.

2010 年, 杜海峰小组 ${ }^{[30]}$ 从 $L$-酒石酸二乙酯 $(60)$ 出 发, 通过简单的转化合成了一类新型的含末端烯烃的手 性膦烯烃配体 62 (Scheme 8), 实验结果表明，配体 62a 在钯催化的丙二酸二甲酯(38a)对 1,3-二苯基-2-丙烯醇 醋酸酯(39a)的烯丙基取代反应中, 可以以当量的转化 和 $77 \%$ 的对映选择性得到 $(R)$-构型的产物 $28 \mathbf{a}$, 而使用 配体 62e 在相同条件下, 产物的构型发生了翻转. 这表 明金属钯和两个配体的配位模式是不同的，配体中的烯 烃在手性诱导过程中起到了至关重要的作用(Eq. 15). 当使用氮、氧等亲核试剂时，手性膦烯烃配体 $62 \mathrm{c}$ 同样 可以有效地催化反应，并得到优秀的对映选择性.

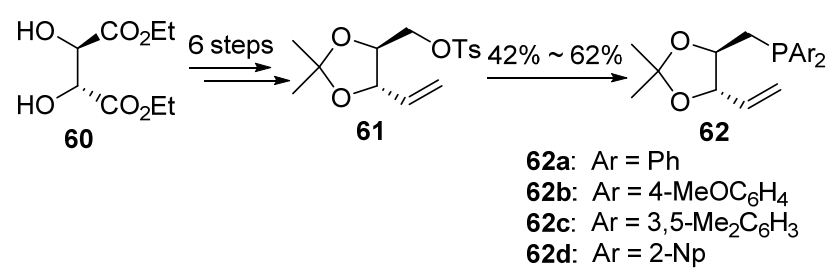

图式 8 含末端烯烃的手性膦烯烃配体的合成

Scheme 8 Synthesis of terminal-alkene-phosphine ligands

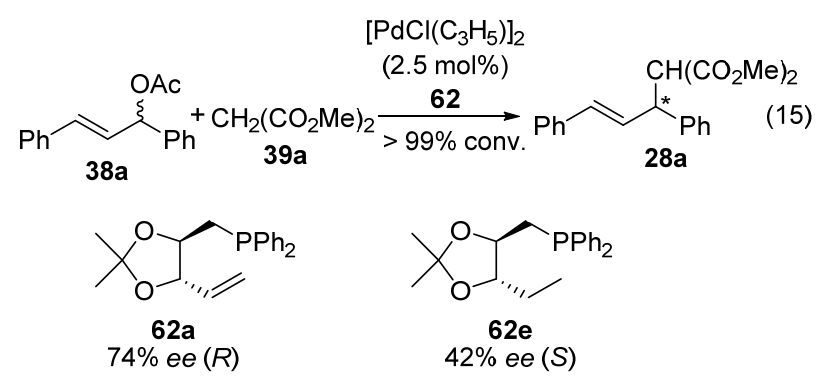<smiles>CCOC(=O)C(Cc1ccccc1)(C(=O)OCC)C(/C=C/c1ccccc1)c1ccccc1</smiles>

随后, 杜海峰小组 ${ }^{[31 \mathrm{a}]}$ 以 $(S)-\mathrm{BINOL}$ 为原料, 经过四 步转化, 合成了基于手性联䒺骨架的膦烯烃配体 64. 吲 哚对烯丙基醋酸酯的不对称烯丙基取代反应中，是一类 有挑战性的底物，末端手性膦烯烃配体 64a 在该类反应 中可以以 $97 \%$ 的产率和 $92 \%$ 的对映选择性得到目标产 物, 含有中间烯烃的配体 $64 \mathrm{~b}$ 则得到中等的产率和相反 的绝对构型. 通过对比实验, 发现配体中的烯烃部分对 保证反应的高活性是至关重要的，使用将乙烯基换为乙 
基的配体 $64 \mathrm{c}$ 时, 反应不能发生. 在相同条件下, 经典 的(S)-MOP 配体 66 也不能促进反应发生(Eq. 16). 除了 吲哚之外, 这类配体在吡咯、4,7-二氢吡咯和肟做亲核 试剂的烯丙基取代反应中, 也有优秀的表现, 可以以很 高的产率和良好的对映选择性得到目标产物 ${ }^{[31 b, 13 \mathrm{c}]}$.
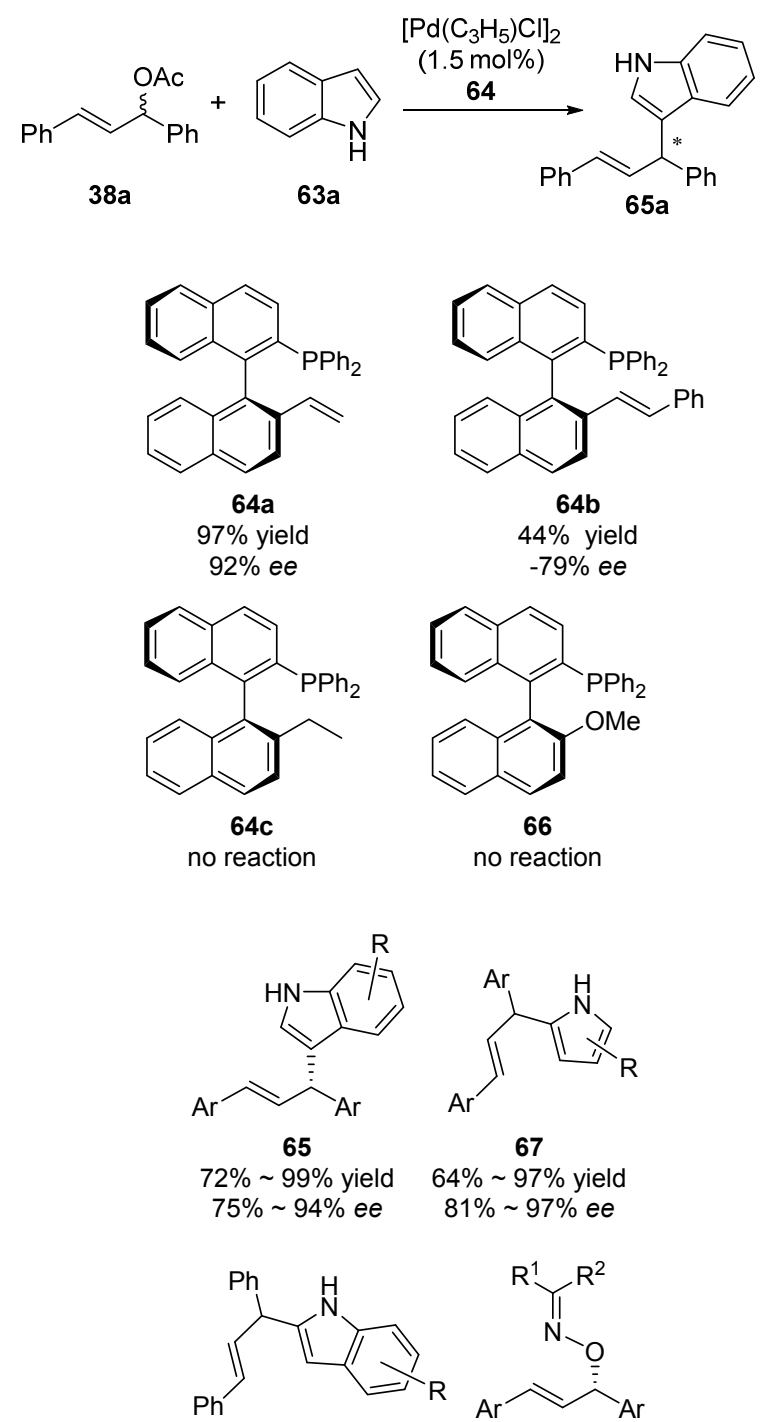

68

$78 \% \sim 88 \%$ yield $86 \% \sim 97 \%$ ee

67

$64 \% \sim 97 \%$ yield

$81 \% \sim 97 \%$ ee

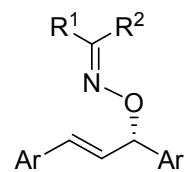

69

$54 \% \sim 99 \%$ yield $83 \% \sim 96 \%$ ee

由于手性亚磷酰胺配体具有易于合成、高稳定性、 用途广泛等优点, 这类配体在不对称催化领域成为一类 “优势配体”. 杜海峰小组将末端烯烃与亚磷酰胺配体结 合起来, 发展了手性膦烯烃配体 71, 这类配体在钯催化 的吲哚对烯丙基醋酸酯的不对称烯丙基取代反应，以及 脂肪胺的不对称烯丙基胺化反应中有优秀的表现. 值得 一提的是, 当使用盐酸着弪胺做氮源时, 反应也能顺利进 行, 并且得到 $95 \%$ 的对映选择性, 这也是首次使用盐酸 着弪胺做亲核试剂实现不对称的烯丙基取代反应 ${ }^{[32 a]}$.

吲哚衍生物通常具有生物和药理活性, 对其区域选

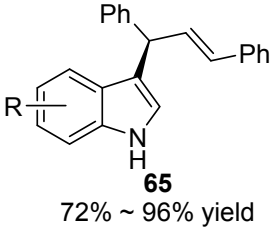

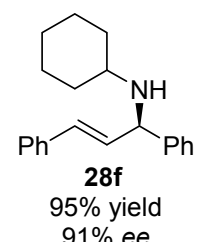<smiles>ON[C@@H](/C=C/c1ccccc1)c1ccccc1</smiles><smiles>C=C(c1ccccc1)N(Cc1ccccc1)P(Oc1c(-c2ccccc2)cc2ccccc2c1-c1ccccc1)c1ccccc1</smiles>

择性和对映选择性的官能化是合成化学中一个重要的 课题. 杜海峰小组将 3-取代吲哚做亲核试剂对烯丙基碳 酸酯取代, 成功实现了钯/亚磷酰胺-烯烃配体催化的 3取代吲哚对烯丙基碳酸酯的不对称烯丙基取代反应，可 以以 76\% 97\%的产率和高达 $87 \%$ 的对映选择性得到含 有手性季碳中心的吲哚衍生物 74. 此外, 这一方法学还 可以用于天然产物 Angelicastigmin 类似物的合成中, 为 该类化合物的合成提供了一个简单的方法(Eq. 17 ${ }^{[326]}$.
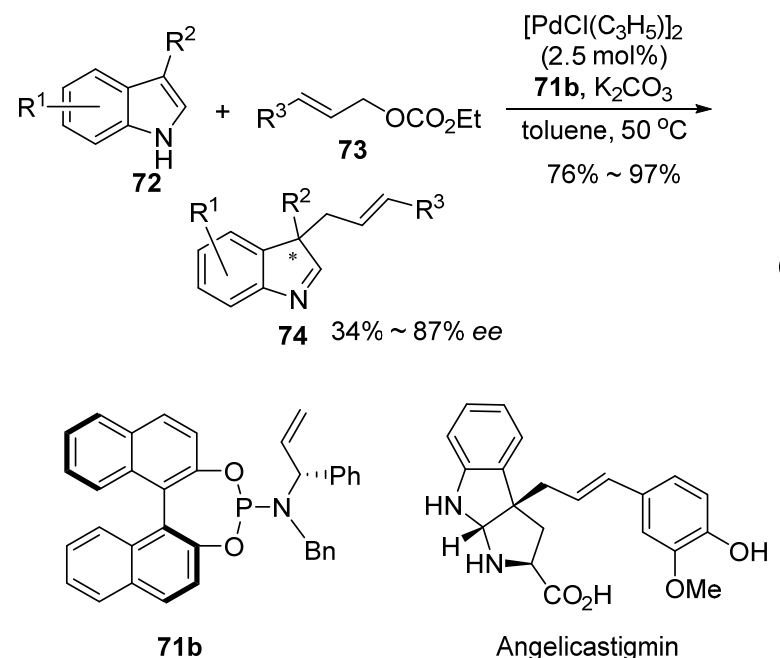

最近, 徐明华小组 ${ }^{[33 a]}$ 将简单的烯烃与联菱骨架的 亚磷酸酯结合，发展了一类新型的磷烯烃配体，末端苯 基取代的配体 76a 可以高效高选择性地催化芳基喼酸 对 1,2-二芳基酮的加成反应，最高可以得到 $96 \%$ 的 $e e$ (Eq. 18). 此外, 通过改变烯烃上的取代基，这类配体还 可以催化芳基或芳基乙烯基硼酸对环状 $N$-磺酰亚胺的 1,2-加成反应，对不同取代的底物和嗍酸，反应都能顺 利的发生, 得到优秀的对映选择性.

\section{3 手性硫烯烃配体}

将杂原子引入烯烃配体之后，配体可以更好地与金 属络合，使其在某些反应中表现出优于传统的磷、氮配 体的活性和选择性，因此发展这样的混合型的烯烃配体 


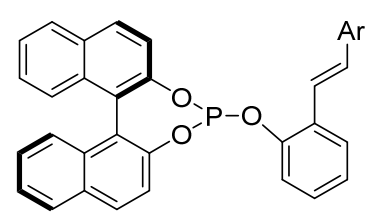

76b: $\mathrm{Ar}=4-\mathrm{PhC}_{6} \mathrm{H}_{4}$ 76c: $\mathrm{Ar}=2$-naphthyl

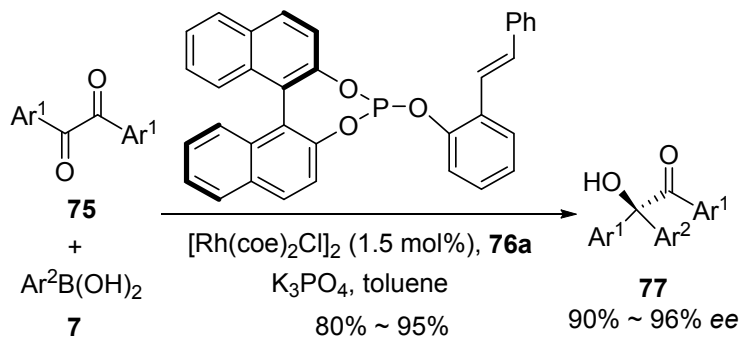

是非常必要的. 此前引入的杂原子还局限于磷和氮原 子, 发展含有其他杂原子的烯烃配体, 为提高不对称反 应的活性和选择性提供了可能.

2011 年, 手性硫烯配体首次被报道快速发展起来, 国内外一些小组都在这一领域展开了工作 ${ }^{[34]}$. 比如: Knochel 小组 ${ }^{[35]}$ 发展的基于降冰片烯骨架的亚砜烯烃配 体, 杜海峰小组 ${ }^{[36]}$ 和徐明华小组 ${ }^{[37]}$ 发展的基于亚磺酰 胺硫手性骨架的硫烯烃配体, 以及廖建 ${ }^{[38]}$ 、万伯顺 ${ }^{[39]}$ 等小组发展的以苯环为骨架的手性亚砜烯烃配体等 ${ }^{[40]}$, 其中配体的硫手性对反应的活性和选择性都起到了非 常重要的作用.
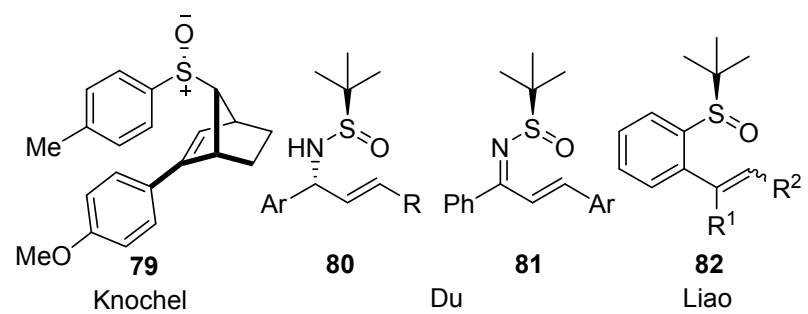

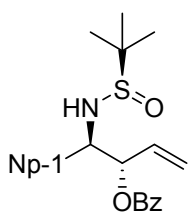

83<smiles>COc1cc(/C=C/c2ccccc2)c(S(=O)(=O)C(C)(C)C)c(OC)c1OC</smiles>

84<smiles>[R]C=C([R])CNS(=O)C(C)(C)C</smiles>

85<smiles>[R][R](=O)c1cc[R]([R16])cc1/C=C/Br</smiles>

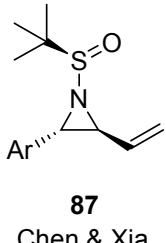<smiles>O=S1(=O)N[C@H](/C=C/c2ccccc2)c2ccccc2O1</smiles>

$78 \mathbf{a}$<smiles>COc1ccc2c(c1)OS(=O)(=O)NC2/C=C/c1ccccc1</smiles>

$87 \%, 92 \%$ ee<smiles>O=S1(=O)N[C@@H](c2ccccc2)c2ccccc2O1</smiles>

$78 \mathrm{c}$ $97 \%, 98 \%$ ee<smiles>Cc1cccc2c1OS(=O)(=O)N[C@H]2c1ccccc1</smiles>

78d

$96 \%, 97 \%$ ee<smiles>O=S1(=O)NC(c2ccsc2)c2ccccc2O1</smiles>

$78 \mathrm{e}$

以上这些手性硫烯烃配体在 $\mathrm{Rh}(\mathrm{I})$-催化的不对称 Hayashi-Mayaura 反应中, 都有优秀的表现，可以以较高 的产率和对映选择性得到 1,4-加成产物. 值得一提的是, 杜海峰小组发展的含有末端双键的手性硫烯烃配体 80a 和含有中间烯烃的配体 $\mathbf{8 0 b}$, 这两个配体具有相同的绝 对构型，但是在催化反应时却得到了构型相反的加成产 物, 这可能是由于烯烃部分的空间位阻引起的. 我们还 得到了配体 $80 \mathrm{~b}$ 与 $\left[\mathrm{RhCl}\left(\mathrm{C}_{2} \mathrm{H}_{4}\right)_{2}\right]_{2}$ 的络合物的单晶结构, 证实了硫原子和烯烃与金属铑的配位 ${ }^{[36 a]}$. 廖建等 ${ }^{[38 a]}$ 发 展的配体 82a 和 $82 \mathrm{~b}$ 在催化反应时，也得到了相似的结 果. 通过改变烯烃的空间位阻就可以改变产物的绝对构 型，这也为通过改变配体得到两种不同的异构体提供的 简单的途径.

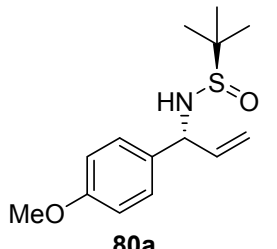

$80 a$

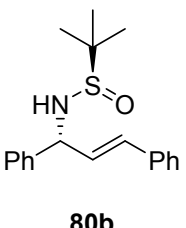

$80 \mathrm{~b}$

80a: $d r=99 / 1>99 \%$ conv, $93 \%$ ee $(R)$ $d r=54 / 46>99 \%$ conv, $92 \%$ ee $(R)$ 80b: $d r=92 / 8 \quad 84 \%$ conv, $94 \%$ ee $(S)$ $d r=55 / 4579 \%$ conv, $94 \%$ ee $(S)$

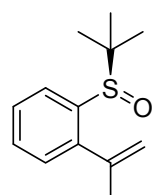<smiles>O=C1CC[C+](c2ccccc2)[C+](c2ccccc2)C1</smiles><smiles>C/C=C/c1ccccc1S(=O)C(C)(C)C</smiles>

82b

$98 \%$ yield $>99 \%$ ee $(R)$
$93 \%$ yield $98 \%$ ee $(S)$

对照试验表明，手性硫烯烃配体 $\mathbf{8 0}$ 的碳手性，对反 应的活性和选择性几乎没有影响. 因此, 我们发展了通 过一步缩合反应得到更简单的配体 81, 这类配体同样 可以高效地用于铑催化的不对称 1,4-加成反应，最高可 以得到 $98 \%$ 的对映选择性 ${ }^{[36 b]}$.

最近, Fernández 小组 ${ }^{[40]}$ 将亚磺酰胺骨架的手性硫 
烯烃配体 85a 用于水相的铑催化的 1,4-加成和 1,2-加成 反应中, 在体系中加入 PTS 等表面活性剂, 可以以当量 的转化和 $99 \%$ 的对映选择性得到加成产物, 而同样条件 下, 使用 $(S)$-BINAP, 反应的活性和选择性都有大幅度 的降低.

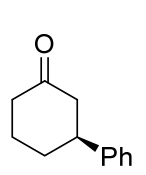

$8 a$

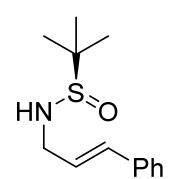

$2.5 \mathrm{~mol} \% 85 \mathrm{a}$ quant, $99 \%$ ee

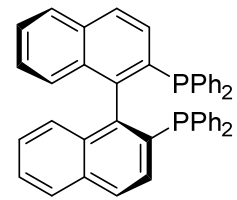

5 mol\% (S)-BINAP 88 $11 \%, 22 \%$ ee<smiles>Cc1c(C)c(OC(=O)CCC(=O)OCCOc2ccccc2)c(C)c2c1CCC(CCCC(C)CCCC(C)CCCC(C)C)(CCCC(C)CCOc1ccccc1)O2</smiles>

Hayashi-Miyaura 反应中, 对非活化的 $\alpha, \alpha, \beta$-三取代 的烯烃的加成是比较困难的, 杜海峰小组 ${ }^{[36 c]}$ 使用手性 硫烯配体 $80 \mathrm{~b}$, 成功实现了铑催化的芳基硼酸对有位阻 的 Morita-Baylis-Hillman 加成产物 89 的不对称共轭加 成- $\beta$-羟基消除反应(Eq. 19). 首次发现这一反应中存在 动力学拆分现象, 其选择性因子最高可达 419 , 反应最 终可以以高达 $99 \%$ 的对映选择性得到高度官能化的烯 烃 90, 拆分的 MBH 醇 89 也可获得高达 97\%的对映选 择性.

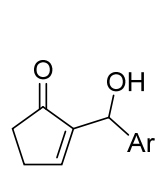

$( \pm)-89$
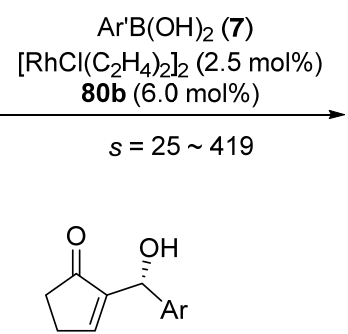

(R)-89

up to $97 \%$ ee

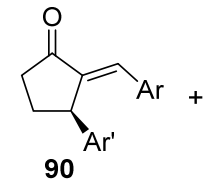

up to $99 \%$ ee
万伯顺小组 ${ }^{[396]}$ 将手性硫烯烃配体 86a 应用于铑催 化的芳基硼酸 7 对硝基苯乙烯类化合物 91 的 1,4-加成 反应中, 以 $50 \% \sim 96 \%$ 的产率和 $82 \% \sim 91 \%$ 的对映选择 性得到加成产物 92 (Eq. 20). 随后, 该小组 ${ }^{[39 c]}$ 还将配体 86b 用于链状不饱和酯的共轭加成反应中, 最高可以得 到 91\%的对映选择性(Eq. 21).

过渡金属催化的有机金属试剂对邻二羰基化合物 的加成, 可以得到 $\alpha$-羟基羰基化合物, 这类结构通常具 有生理活性, 在天然产物中广泛存在, 并在合成化学中 有广泛的用途. 2012 年, 徐明华小组 ${ }^{[37 \mathrm{~d}]}$ 使用配体 84, 实 现了铑催化的芳基硼酸 7 对 $\alpha$-酮酸酯和 1,2 二酮的加成

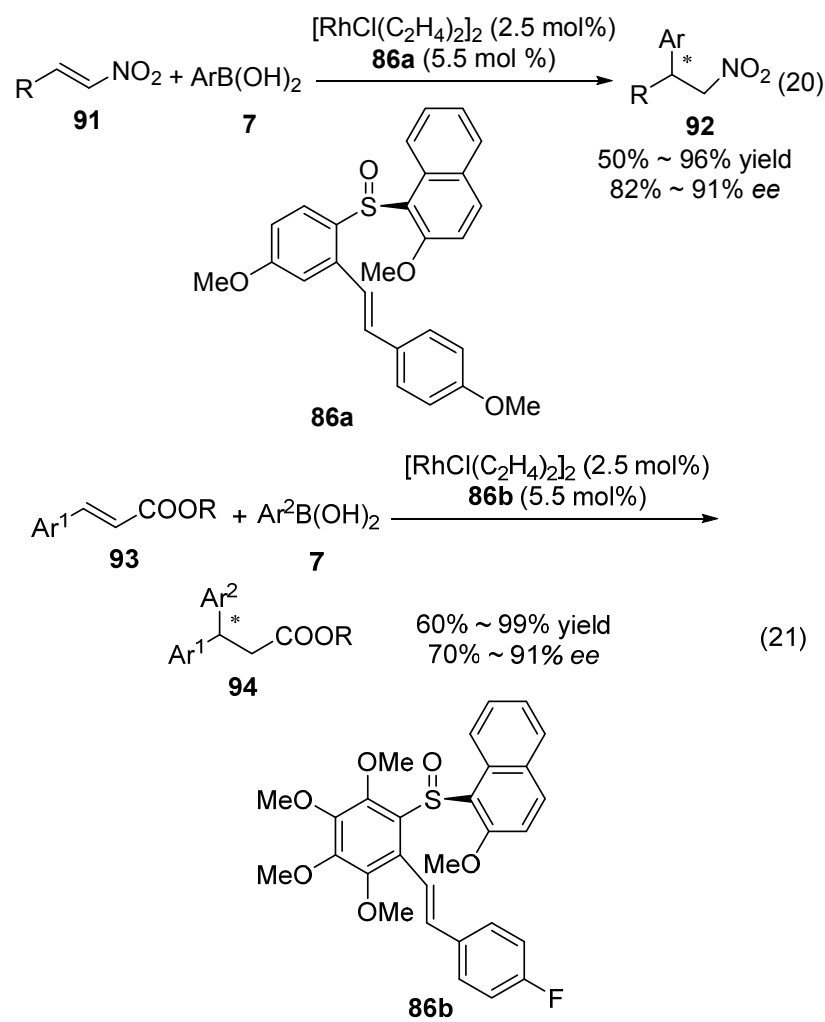

反应，可以以 $45 \% \sim 99 \%$ 的产率和 $63 \% \sim 99 \%$ 的对映选 择性得到一系列 $\alpha$-羟基羰基化合物 77 (Eq. 22). 加成产 物通过简单的转化, 可以得到具有抗抑郁活性的手性 1,3-二羟基异苯并呋喃，并保持原来的光学活性.

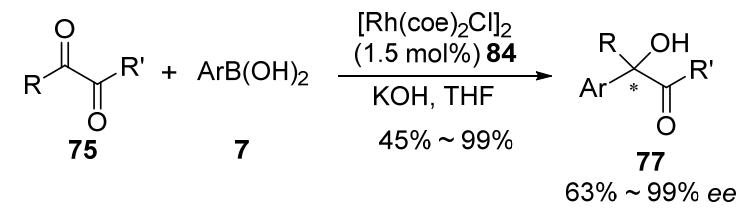

几乎同时, 杜海峰小组 ${ }^{[36 \mathrm{~d}]}$ 对该类反应也进行了报 道，将手性硫烯配体 80b 应用于铑催化的芳基硼酸 7 对 1,2-二酮化合物 75 的 1,2-加成反应中，在 $0.1 \%$ 的催化剂 用量下，以 $56 \% \sim 99 \%$ 的产率和 $97 \% \sim 99 \%$ 的对映选择 性得到加成产物(Eq. 23), 提供了一类高效高对映选择 性的合成手性 $\alpha$-羰基季碳醇的方法.

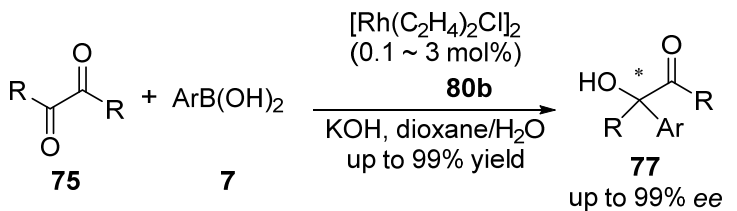

2013 年, 徐明华小组 ${ }^{[37]}$ 将配体 85 用于 $\alpha$-酮酸酯的 1,2-加成反应，可以以中等的产率和对映选择性得到含 季碳的 $\alpha$-羟基酯. 值得一提的是, 通过改变配体上的取 代基，可以改变对底物加成的位置，合成不同的手性醇 (Eqs. 24, 25). 


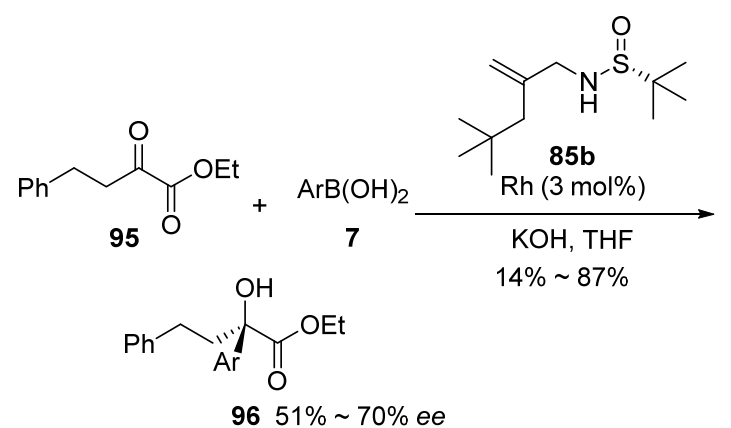<smiles>[R]C=CC(=O)O[R]</smiles><smiles>COc1ccc(Br)cc1</smiles>

$7 b$<smiles>C=C(CNS(=O)C(C)(C)C)Cc1c2ccccc2cc2ccccc12</smiles>

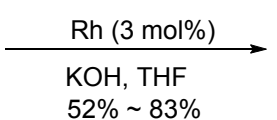<smiles>[R]C=CC(O)(C(=O)O[R2])c1ccc(OC)cc1</smiles>

在以上工作基础上, 徐明华小组 ${ }^{[37 \mathrm{~g}]}$ 通过改变手性 硫烯烃配体烯烃上的取代基, 发现配体 $85 \mathrm{~b}$ 还可以高效 地催化芳基嗍酸对邻位取代的 $\alpha$-酮酸酯的 1,2-加成反 应, 经过简单的化学转化合成 3-芳基-3-差基吲哚酮、 1,3-二氢异苯并呋喃和 3-异色酮等化合物及其衍生物 (Schemes 9, 10).<smiles>CC(C)(C)COC(=O)c1ccccc1NC(=O)OCc1ccccc1</smiles>

99

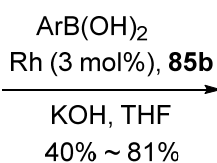

$\mathrm{KOH}, \mathrm{THF}$
$40 \% \sim 81 \%$<smiles>C1CCCCC1</smiles>

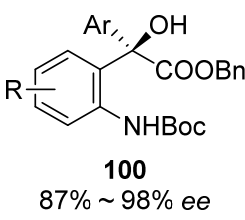

$87 \% \sim 98 \%$ ee

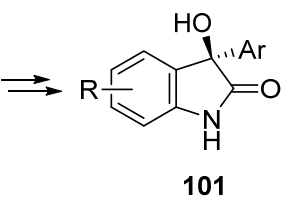

图式 93 -芳基-3-着基吲哚酮衍生物的合成 Scheme 9 Synthesis of chiral 3-aryl-3-hydroxyoxindole derivatives

对于简单的酮类底物, 由于羰基两侧的位阻差别比 较小, 芳基硼酸对酮的 1,2-加成反应的活性比较低, 因 此这类反应也比较困难 ${ }^{[41]}$. Lam 小组 ${ }^{[42]}$ 利用末端手性硫 烯配体 80c, 实现了铑催化的分子内的硼试剂对酮 105 的加成环化反应, 合成了一系列四氢异喹啉-4-醇 106 (Eq. 26).

含有 3-芳基-3-羟基-2-吲哚酮结构的化合物广泛地 存在于天然产物和一些具有生物活性的药物中, 由于它

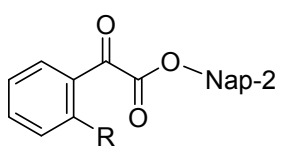

102

$\mathrm{R}=\mathrm{Me}$ or $\mathrm{CH}_{2} \mathrm{OMOM}$

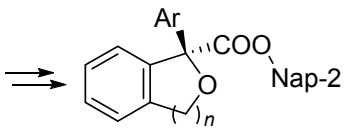

$n=1,2$

104
$\operatorname{ArB}(\mathrm{OH})_{2}$

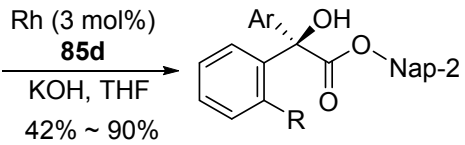

103

$86 \% \sim 96 \%$ ee

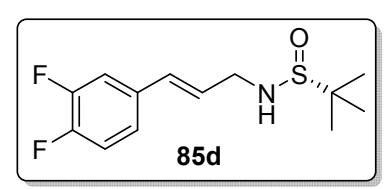

图式 10 1,3-二氢异苯并呋喃和 3-异色酮等化合物的合成 Scheme 10 Synthesis of chiral 1,3-dihydroisobenzofuran and 3-isochromanone derivatives

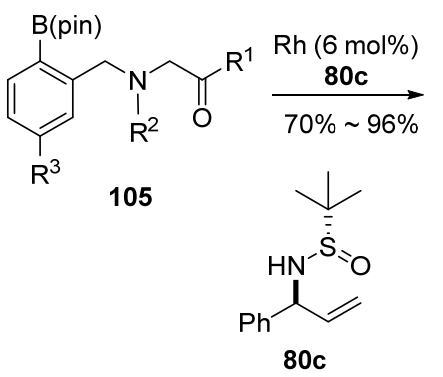<smiles>[R]c1ccc2c(c1)CN([R])CC2([R1])O</smiles>

106 $80 \% \sim 92 \%$ ee
们通常具有非常优秀的生理活性, 因此引起了化学家们 的重视, 发展了一系列手性合成的策略, 其中有机金属 试剂对靛红的加成反应是最直接有效的合成方法 ${ }^{[41]}$. 杜海峰小组 ${ }^{[36 f]}$ 将手性硫烯配体 80b 用于芳基硼酸对靛 红及其衍生物的 1,2-加成反应中，可以以中等到优秀的 产率和 $51 \% \sim 85 \%$ 的对映选择性得到加成产物. 以加成 产物为关键中间体，这一方法学还被拓展用于手性药物 109 的合成, 进一步丰富了手性硫烯烃配体的应用 (Scheme 11).

徐明华小组 ${ }^{[37 \mathrm{e}]}$ 将简单的支链手性亚磺酰胺烯烃配 体 85e, 用于铑催化的芳基硼酸对环状酮亚胺的芳基化 反应中, 可以以优秀的对映选择性得到各种类型的含有 手性季碳中心的苯并内磺酰胺类化合物. 这也是首次使 用手性硫烯烃配体实现对亚胺的加成反应.

1,1-二氧-1,2,5-噻二唑啉衍生物也具有环状酮亚胺 的结构, 不仅是药物化学中常见的结构, 而且可以用于 环状磺酰胺、1,2-二胺以及 $\alpha$-氨基酸的合成, 是重要的 合成化学中间体 ${ }^{[43]}$. 徐明华小组 ${ }^{[37 \mathrm{~h}]}$ 将配体 $85 \mathrm{e}$ 用于铑 催化的芳基硼酸对 3,4-噻二唑 114 的加成反应中, 可以 在温和的反应条件下得到高达 $99 \%$ 的产率和对映选择 性. 值得一提的是, 对非对称的 3,4-噻二唑底物 116, 加 成位置不受电子效应和位阻的影响, 两个加成产物都可 以以很高的对映选择性得到, 并通过柱层析分离(Eqs. 27, 28). 
<smiles>COc1ccccc1O[18O]c1ccccc1OC</smiles><smiles>COc1ccccc1C1(O)C(=O)Nc2ccc(Cl)cc21</smiles>

after a recrystallization<smiles>COc1ccccc1C1(OC(=O)N2CCN(c3ccccn3)CC2)C(=O)N(S(=O)(=O)c2cccc3cccnc23)c2ccc(Cl)cc21</smiles>

109

图式 11 手性化合物 109 的合成

Scheme 11 Synthesis of compound 109<smiles>[R]COC(=O)C1([Al])NS(=O)(=O)C2=C1C=C[R]C=C2</smiles>

110 $35 \% \sim 96 \%$ yield $85 \% \sim 99 \%$ ee<smiles></smiles>

113 $96 \% \sim 99 \%$ yield $99 \%$ ee<smiles>O=S1(=O)N[C@@]([18F])([Al])c2ccccc2O1</smiles>

112 $72 \% \sim 91 \%$ yield $\quad 26 \% \sim 84 \%$ yield $95 \% \sim 98 \%$ ee $\quad 98 \% \sim 99 \%$ ee<smiles>C=C(CNS(=O)C(C)(C)C)Cc1cccc2ccccc12</smiles>
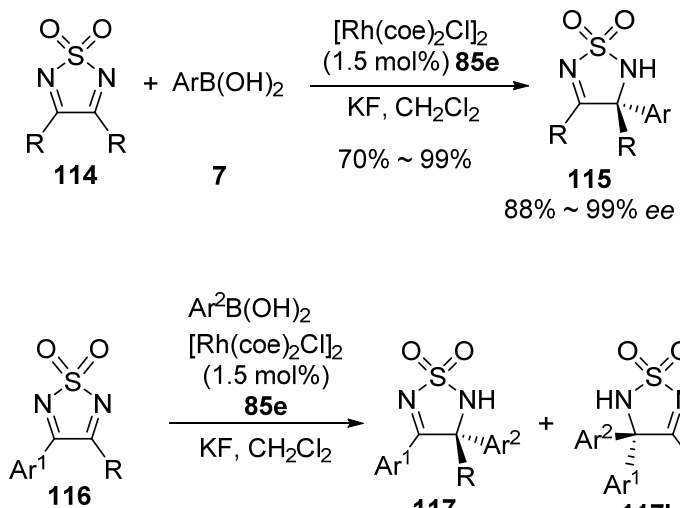

$$
\mathrm{Ar}^{2} \mathrm{~B}(\mathrm{OH})_{2}
$$$$
\underset{\mathrm{KF}, \mathrm{CH}_{2} \mathrm{Cl}_{2}}{\begin{array}{c}
\mathrm{Rh}(\mathrm{coe})_{2} \mathrm{Cl}_{2} \\
(1.5 \mathrm{~mol} \%)
\end{array}}
$$

金属催化的乙烯基环氧乙烷与亚胺的 $[3+2]$ 环加成 反应是制备噁唑烷的有效方法. 杜海峰小组 ${ }^{[36 e]}$ 将手性 硫烯烃配体 $81 b$ 应用于铑催化的亚胺 119 和 120 与消旋

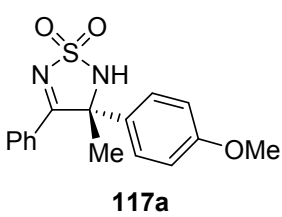

$53 \%, 90 \%$ ee<smiles>COc1ccc(C2(c3ccccc3)NS(=O)(=O)N=C2c2ccc(C)cc2)cc1</smiles>

$117 \mathbf{b}$

$35 \%, 95 \%$ ee<smiles>COc1ccc([C@]2(c3ccccc3)NS(=O)(=O)N=C2C)cc1</smiles>

$117 a^{\prime}$

$41 \%, 75 \%$ ee<smiles>COc1ccc([C@]2(c3ccc(C)cc3)NS(=O)(=O)N=C2c2ccccc2)cc1</smiles>

的乙烯基环氧乙烷 118 的[3+2]不对称环加成中, 反应 过程中同时存在动态动力学和动力学拆分过程. 对 isatin 衍生的亚胺，加成产物可以达到 $61 \% \sim 91 \%$ 的产 率和 $78 \% \sim 96 \%$ 的对映选择性，且 $d r$ 值大部分保持在 $20 ： 1$. 对普通亚胺的环加成反应, 得到的大部分主要 为反式加成产物的噁唑烷，产率最高可达 90\%，对映选 择性最高可达 $97 \%$, 对大部分底物可以得到中等的 $d r$ 值, 最高达 $10 ： 1$ (Scheme 12).

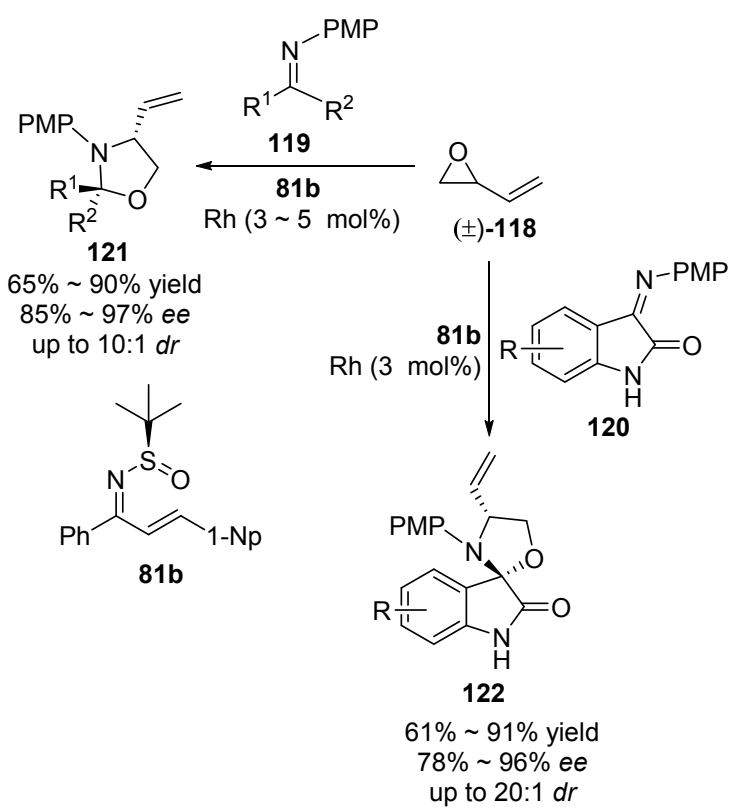

图式 12 铑催化的亚胺与消旋乙烯基环氧乙烷的不对称环加 成反应

Scheme 12 Rhodium-catalyzed asymmetric cycloadditions of racemic butadiene monoxide with imines

\section{4 总结与展望}

在过去十几年间，手性烯烃配体在不对称催化领域 得到了快速的发展. 除了常用的含有刚性骨架的双烯配 体，具有柔性开链骨架的双烯具有易于合成和修饰的优 
点, 这类配体通常以末端烯烃作为配位基团, 在铑催化 的加成反应中有优秀的表现, 可以得到非常高的对映选 择性. 此外, 烯烃与磷原子的结合为发展新型的手性膦 烯烃配体提供了新的策略, 这类配体在钯催化的不对称 烯丙基取代反应中通常可以表现出高的活性和选择性. 值得一提的是, 在铱催化的不对称烯丙基取代中, 联萗 骨架的亚膦酰胺烯烃配体是一类高效的配体, 对各种底 物都可以得到优秀的区域选择性和对映选择性. 作为一 类新兴的配体, 手性硫烯烃配体在铑催化的不对称转化 中表现出一些独特的优势. 然而, 与其他类型的手性配 体相比, 烯烃配体的应用范围仍然比较窄. 发展更加有 效的烯烃配体并拓展它们在过渡金属催化的反应中的 应用仍然是这一领域最重要的两大科学问题.

\section{References}

[1] Jia, X.; Wang, Z.; Xia, C.; Ding, K. Chin. J. Org. Chem. 2013, 33, 1369 (in Chinese) (贾肖飞, 王正, 夏春谷, 丁奎岭, 有机化学, 2013, 33, 1369.)

[2] For leading reviews on chiral olefin ligands, see: (a) Glorius, F. Angew. Chem., Int. Ed. 2004, 43, 3364.

(b) Johnson, J. B.; Rovis, T. Angew. Chem., Int. Ed. 2008, 47, 840. (c) Defieber, C.; Grützmacher, H.; Carreira, E. M. Angew. Chem., Int. Ed. 2008, 47, 4482.

(d) Shintani, R.; Hayashi, T. Aldrichim. Acta 2009, 42, 31. (e) Feng, C.-G.; Xu, M.-H.; Lin, G.-Q. Synlett 2011, 1345. (f) Tian, P.; Dong, H.-Q.; Lin, G.-Q. ACS Catal. 2012, 2, 95. (g) Feng, X.; Du, H. Asian J. Org. Chem. 2012, 1, 204. (h) Li, Y.; Xu, M.-H. Chem. Commun. 2014, 50, 3771.

[3] (a) Hayashi, T.; Ueyama, K.; Tokunaga, N.; Yoshida, K. J. Am Chem. Soc. 2003, 125, 11508.

(b) Fischer, C.; Defieber, C.; Suzuki, T.; Carreira, E. M. J. Am. Chem. Soc. 2004, 126, 1628.

[4] (a) Wang, Z.-Q.; Feng, C.-G.; Xu, M.-H.; Lin, G.-Q. J. Am. Chem. Soc. 2007, 129, 5336.

(b) Feng, C.-G.; Wang, Z.-Q.; Shao, C.; Xu, M.-H.; Lin, G.-Q. Org. Lett. 2008, 10, 4101.

(c) Shao, C.; Yu, H.-J.; Wu, N.-Y.; Feng, C.-G.; Lin, G.-Q. Org. Lett. 2010, 12, 3820.

[5] Hu, X.; Zhuang, M.; Cao, Z.; Du, H. Org. Lett. 2009, 11, 4744.

[6] For leading references on $\operatorname{Pd}(0)$-catalyzed diamination, see: (a) Du, H.; Zhao, B.; Shi, Y. J. Am. Chem. Soc. 2007, 129, 762.

(b) Du, H.; Yuan, W.; Zhao, B.; Shi, Y. J. Am. Chem. Soc. 2007, 129, 7496.

(c) Du, H.; Yuan, W.; Zhao, B.; Shi, Y. J. Am. Chem. Soc. 2007, 129, 11688.

(d) Du, H.; Zhao, B.; Shi, Y. J. Am. Chem. Soc. 2008, 130, 8590.

(e) Wang, B.; Du, H.; Shi, Y. Angew. Chem., Int. Ed. 2008, 47, 8224 .

(f) Zhao, B.; Du, H.; Cui, S.; Shi, Y. J. Am. Chem. Soc. 2010, 132, 3523.

[7] Hu, X.; Cao, Z.; Liu, Z.; Wang, Y.; Du, H. Adv. Synth. Catal. 2010, 352,651 .

[8] Wang, Y.; Hu, X.; Du, H. Org. Lett. 2010, 12, 5482.

[9] (a) Minuth, T.; Boysen, M. M. K. Org. Lett. 2009, 11, 4212.

(b) Grugel, H.; Minuth, T.; Boysen, M. M. K. Synthesis 2010, 19, 3248.
[10] (a) Li, Q.; Yu, Z.-X. Angew. Chem., Int. Ed. 2011, 50, 2144. (b) Li, Q.; Dong, Z.; Yu, Z.-X. Org. Lett. 2011, 13, 1122.

[11] Trost, B. M.; Burns, A. C.; Tautz, T. Org. Lett. 2011, 13, 4566.

[12] Fairhurst, N. W. G.; Munday, R. H.; Carbery, D. R. Synlett, 2013, 24, 496.

[13] Cao, Z.; Du, H. Org. Lett. 2010, 12, 2602.

[14] (a) Mariz, R.; Briceño, A.; Dorta, R.; Dorta, R. Organometallics 2008, 27, 6605; (b) Kasák, P.; Arion, V. B.; Widhalm, M. Tetrahedron: Asymmetry 2006, 17, 3084.

[15] (a) Maire, P.; Deblon, S.; Breher, F.; Geier, J.; Böhler, C.; Rüegger, H.; Schönberg, H.; Grützmacher, H. Chem.-Eur. J. 2004, 10, 4198. (b) Piras, E.; Läng, F.; Rüegger, H.; Stein, D.; Wörle, M.; Grützmacher, H. Chem.-Eur. J. 2006, 12, 5849.

[16] (a) Shintani, R.; Duan, W.-L.; Nagano, T.; Okada, A.; Hayashi, T. Angew. Chem., Int. Ed. 2005, 44, 4611.

(b) Duan, W.-L.; Iwamura, H.; Shintani, R.; Hayashi, T. J. Am. Chem. Soc. 2007, 129, 2130.

(c) Shintani, R.; Duan, W.-L.; Okamoto, K.; Hayashi, T. Tetrahedron: Asymmetry 2005, 16, 3400.

[17] (a) Shintani, R.; Narui, R.; Tsutsumi, Y.; Hayashi, S.; Hayashi, T. Chem. Commun. 2011, 6123.

(b) Narui, R.; Hayashi, S.; Otomo, H.; Shintani, R.; Hayashi, T. Tetrahedron: Asymmetry 2012, 23, 284.

[18] Štěpnička, P.; Císařová, I. Inorg. Chem. 2006, 45, 8785.

[19] Stemmler, R. T.; Bolm, C. Synlett 2007, 1365.

[20] Ogasawara, M.; Tseng, Y.-Y.; Arae, S.; Morita, T.; Nakaya, T.; Wu, W.-Y.; Takahashi, T.; Kamikawa, K. J. Am. Chem. Soc. 2014, 136, 9377.

[21] (a) Minuth, T.; Boysen, M. M. K. Org. Lett. 2009, 11, 4212.

(b) Grugel, H.; Minuth, T.; Boysen, M. M. K. Synthesis 2010, 3248.

[22] (a) Defieber, C.; Ariger, M. A.; Moriel, P.; Carreira, E. M. Angew. Chem., Int. Ed. 2007, 46, 3139.

(b) Roggen, M.; Carreira, E. M. J. Am. Chem. Soc. 2010, 132, 11917.

[23] Roggen, M.; Carreira, E. M. Angew. Chem., Int. Ed. 2011, 50, 5568 .

[24] Hamilton, J. Y.; Sarlah, D.; Carreira, E. M. Angew. Chem., Int. Ed. 2013, 52, 7532.

[25] (a) Schafroth, M. A.; Sarlah, D.; Krautwald, S.; Carreira, E. M. J. Am. Chem. Soc. 2012, 134, 20276.

(b) Jeker, O. F.; Kravina, A. G.; Carreira, E. M. Angew. Chem., Int. Ed. 2013, 52, 12166.

[26] Hamilton, J. Y.; Sarlah, D.; Carreira, E. M. J. Am. Chem. Soc. 2014, 136, 3006.

[27] Hoffman, T. J.; Carreira, E. M. Angew. Chem. Int. Ed. 2011, 50, 10670.

[28] Krautwald, S.; Sarlah, D.; Schafroth, M. A.; Carreira, E. M. Science, 2013, 340, 1065.

[29] Krautwald, S.; Schafroth, M. A.; Sarlah, D.; Carreira, E. M. J. Am. Chem. Soc. 2014, 136, 3020.

[30] Liu, Z.; Du, H. Org. Lett. 2010, 12, 3054.

[31] (a) Cao, Z.; Liu, Y.; Liu, Z.; Feng, X.; Zhuang, M.; Du, H. Org. Lett. 2011, 13, 2164;

(b) Cao, Z.; Liu, Z.; Liu, Y.; Du, H. J. Org. Chem. 2011, 76, 6401; (c) Liu, Y.; Cao, Z.; Du, H. J. Org. Chem. 2012, 77, 4479.

[32] (a) Liu, Z.; Cao, Z.; Du, H. Org. Biomol. Chem. 2011, 9, 5369.

(b) Liu, Y.; Du, H. Org. Lett. 2013,15,740.

[33] (a) Yu, Y.-N.; Xu, M.-H. Org. Chem. Front. 2014, 1, 738.

(b) Yu, Y.-N.; Xu, M,-H. Acta Chim. Sinica 2014, 72, 815 (in Chinese).

(于月娜, 徐明华, 化学学报, 2014, 72, 815.)

[34] (a) Li, Y.; Xu, M.-H. Chem. Commun. 2014, 50, 3771. 
(b) Chen, Q.; Chen, C.; Guo, F.; Xia, W. Chem. Commun. 2013, 49, 6433.

[35] Thaler, T.; Guo, L.-N.; Steib, A. K.; Raducan, M.; Karaghiosoff, K.; Mayer, P.; Knochel, P. Org. Lett. 2011, 13, 3182.

[36] (a) Feng, X.; Wang, Y.; Wei, B.; Yang, J.; Du, H. Org. Lett. 2011, 13, 3300 .

(b) Feng, X.; Wei, B.; Yang, J.; Du, H. Org. Biomol. Chem. 2011, $9,5927$.

(c) Wang, Y.; Feng, X.; Du, H. Org. Lett. 2011, 13, 4954.

(d) Feng, X.; Nie, Y.; Yang, J.; Du, H. Org. Lett. 2012, 14, 624.

(e) Liu, Z.; Feng, X.; Du, H. Org. Lett. 2012, 14, 3154.

(f) Feng, X.; Nie, Y.; Zhang, L.; Yang, J.; Du, H. Tetrahedron Lett. 2014, 55, 4581

[37] (a) Jin, S.-S.; Wang, H.; Xu, M.-H. Chem. Commun. 2011, 47, 7230

(b) Qi, W.-Y.; Zhu, T.-S.; Xu, M.-H. Org. Lett. 2011, 13, 3410.

(c) Jin, S.-S.; Wang, H.; Zhu, T.-S.; Xu, M.-H. Org. Biomol. Chem. 2012, 10, 1764

(d) Zhu, T.-S.; Jin, S.-S.; Xu, M.-H. Angew. Chem., Int. Ed. 2012, 51,780 .

(e) Wang, H.; Jiang, T.; Xu, M.-H. J. Am. Chem. Soc. 2013, 135, 971.

(f) Zhu, T.-S.; Xu, M.-H. Chin. J. Chem. 2013, 31, 321.

(g) Li, Y.; Zhu, D.-X.; Xu, M.-H. Chem. Commun. 2013, 49, 11659; (h) Wang, H.; Li, Y.; Xu, M.-H. Org. Lett. 2014, 16, 3962.

[38] (a) Chen, G.; Gui, J.; Li, L.; Liao, J. Angew. Chem., Int. Ed. 2011, 50, 7681 .

(b) Chen, G.; Gui, J.; Cao, P.; Liao, J. Tetrahedron 2012, 68, 3220.

[39] (a) Xue, F.; Li, X.; Wan, B. J. Org. Chem. 2011, 76, 7256

(b) Xue, F.; Wang, D.; Li, X.; Wan, B. J. Org. Chem. 2012, 77, 3071

(c) Xue, F.; Wang, D.; Li, X.; Wan, B. Org. Biomol. Chem. 2013,
$11,7893$.

[40] Khiar, N.; Valdivia, V.; Salvador, Á.; Chelouan, A.; Alcudia, A.; Fernández, I. Adv. Synth. Catal. 2013, 355, 1303.

[41] (a) Shintani, R.; Inoue, M.; Hayashi, T. Angew. Chem., Int. Ed. 2006, 45, 3353.

(b) He, P.; Lu, Y.; Dong, C.-G.; Hu, Q.-S. Org. Lett. 2007, 9, 343.

(c) Duan, H.-F.; Xie, J.-H.; Qiao, X.-C.; Wang, L.-X.; Zhou, Q.-L. Angew. Chem., Int. Ed. 2008, 47, 4351.

(d) Cai, F.; Pu, X.; Qi, X.; Lynch, V.; Radha, A.; Ready, J. M. J. Am. Chem. Soc. 2011, 133, 18066.

(e) Oi, S.; Moro, M.; Furuhara, H.; Kawanishi, T.; Inoue, Y. Tetrahedron 2003, 59, 4351

(f) Ganci, G. R.; Chisholm, J. D. Tetrahedron Lett. 2007, 48, 8266.

(g) Tokunaga, T.; Hume, W. E.; Umezome, T.; Okazaki, K.; Ueki, Y.; Kumgai, K.; Hourai, S.; Nagamine, J.; Seki, H.; Taiji, M.; Noguchi, H.; Nagata, R. J. Med. Chem. 2001, 44, 4641.

(h) González, A.; Quirante, J.; Nieto, J.; Almeida, M. R.; Saraiva, M. J.; Planas, A.; Arsequell, G.; Valencia, G. Bioorg. Med. Chem. Lett. 2009, 19, 5270.

[42] Low, D. W.; Pattison, G.; Wieczysty, M. D.; Churchill, G. H.; Lam, H. W. Org. Lett. 2012, 14, 2548.

[43] (a) Wright, J. B. J. Org. Chem. 1964, 29, 1905.

(b) Rozas, M. F.; Piro, O. E.; Castellano, E. E.; Mirífico, M. V.; Vasini, E. J. Molecules 2000, 5, 503.

(c) Lee, S. A.; Kwak, S. H.; Lee, K.-I. Chem. Commun. 2011, 47 2372 .

(d) Nishimura, T.; Ebe, Y.; Fujimoto, H.; Hayashi, T. Chem. Commun. 2013, 49, 5504

(e) Pansare, S. V.; Rai, A. N.; Kate, S. N. Synlett 1998, 623.

(f) Hepburn, H. B.; Chotsaeng, N.; Luo, Y.; Lam, H. W. Synthesis 2013, 45, 2649.

(g) Lee, C.-H.; Korp, J. D.; Kohn, H. J. Org. Chem. 1989, 54, 3077.

(Lu, Y.) 